\title{
Calcium-Permeable AMPA Receptors in the Nucleus Accumbens Regulate Depression-Like Behaviors in the Chronic Neuropathic Pain State
}

\author{
Yossef Goffer, ${ }^{1}$ Duo Xu, ${ }^{1}$ Sarah E. Eberle,${ }^{1}$ James D'amour, ${ }^{2}$ Michelle Lee, ${ }^{1}$ David Tukey, ${ }^{3}$ Robert C. Froemke, ${ }^{2}$ \\ Edward B. Ziff, ${ }^{3}$ and Jing Wang ${ }^{1}$ \\ ${ }^{1}$ Department of Anesthesiology, ${ }^{2}$ Molecular Neurobiology Program, The Helen and Martin Kimmel Center for Biology and Medicine at the Skirball Institute \\ for Biomolecular Medicine, Departments of Otolaryngology and Physiology and Neuroscience, and ${ }^{3}$ Department of Biochemistry, New York University \\ School of Medicine, New York, New York 10016
}

\begin{abstract}
Depression is a salient emotional feature of chronic pain. Depression alters the pain threshold and impairs functional recovery. To date, however, there has been limited understanding of synaptic or circuit mechanisms that regulate depression in the pain state. Here, we demonstrate that depression-like behaviors are induced in a rat model of chronic neuropathic pain. Using this model, we show that chronic pain selectively increases the level of GluA1 subunits of AMPA-type glutamate receptors at the synapses of the nucleus accumbens (NAc), a key component of the brain reward system. We find, in addition, that this increase in GluA1 levels leads to the formation of calcium-permeable AMPA receptors (CPARs). Surprisingly, pharmacologic blockade of these CPARs in the NAc increases depressionlike behaviors associated with pain. Consistent with these findings, an AMPA receptor potentiator delivered into the NAc decreases pain-induced depression. These results show that transmission through CPARs in the NAc represents a novel molecular mechanism modulating the depressive symptoms of pain, and thus CPARs may be a promising therapeutic target for the treatment of pain-induced depression. More generally, these findings highlight the role of central glutamate signaling in pain states and define the brain reward system as an important region for the regulation of depressive symptoms of pain.
\end{abstract}

\section{Introduction}

Depression is a common affective feature of chronic pain, and symptoms such as anhedonia and decreased motivation further impair patient functions (Dworkin and Gitlin, 1991; Miller and Cano, 2009). A better understanding of circuit and synaptic regulation of pain-induced depression is needed.

Human imaging studies have consistently shown that chronic pain activates the nucleus accumbens (NAc; Becerra and Borsook, 2008; Baliki et al., 2010, 2012), a brain region well known to mediate reward-driven behaviors (Kalivas and Volkow, 2005; Fields, 2007). Recently, neurotrophic, metabolic, transcriptional, and epigenetic signaling mechanisms in the NAc have been shown to regulate depressive behaviors in animal studies (Park et al., 2005; Berton et al.,

Received June 10, 2013; revised Oct. 4, 2013; accepted 0ct. 25, 2013.

Author contributions: R.C.F., E.B.Z., and J.W. designed research; Y.G., D.X., S.E.E., J.D., M.L., and D.T. performed research; Y.G., D.X., S.E.E., J.D., M.L., D.T., R.C.F., E.B.Z., and J.W. analyzed data; E.B.Z. and J.W. wrote the paper.

This work was supported by the National Institute for General Medical Sciences (GM102691), the National Institute for Neurologic Disorders and Stroke (NS061920), the Foundation for Anesthesia Education and Research (MRTG-BS-02/15/2010), and the Anesthesia Research Fund of the New York University Department of Anesthesiology. We thank W.-B. Gan and K.D. Carr for their comments on this manuscript.

J.W. and E.B.Z. have filed a patent for the use of AMPA receptor potentiation in the treatment of pain and pain-induced depression. The other authors declare no competing financial interests.

Correspondence should be addressed to Jing Wang, Department of Anesthesiology, New York University School of Medicine, Alexandria Center for Life Science, 450 East 29th Street, Rm 823, New York, NY 10016. E-mail: jing.wang2@nyumc.org.

DOI:10.1523/JNEUROSCI.2454-13.2013

Copyright $\odot 2013$ the authors $\quad 0270-6474 / 13 / 3319034-11 \$ 15.00 / 0$
2006; Nestler and Carlezon, 2006; Lim et al., 2012; Golden et al., 2013). At the circuit level, the NAc forms reciprocal projections with the amygdala, prefrontal cortex (PFC), and hippocampus - critical regions for pain and depression (Pezawas et al., 2005; Bär et al., 2007; Ressler and Mayberg, 2007; Gonçalves et al., 2008; MacQueen and Frodl, 2011; Kim et al., 2012). Given its established role in depression and its circuit connection to other affective pain centers, the NAc may be expected to contribute to the regulation of pain-induced depression.

At the synaptic level, depression profoundly alters central glutamate signaling through AMPA receptors (Skolnick et al., 2009; Sanacora et al., 2012). AMPA receptors are primary mediators of excitatory transmission, and they are composed of four subunits, GluA1-GluA4. Reduced GluA1 levels in the amygdala, PFC, and hippocampus have been found in several rodent stress models of depression (Yuen et al., 2012; Chandran et al., 2013; Duric et al., 2013). In the NAc, decreased levels of GluA2-containing AMPA receptors have been described in depressive states (Vialou et al., 2010; Lim et al., 2012). The importance of AMPA receptor signaling, meanwhile, can be demonstrated by GluA1 knock-out mice, which display vulnerability to depression (Chourbaji et al., 2008), by antidepressants that increase GluA1 and GluA2 expression in the PFC and NAc (Tan et al., 2006; Li et al., 2010a), and by antidepressant properties of AMPA potentiators, which increase AMPA receptor activities (Skolnick, 2008).

The impact that AMPA receptor subunit stoichiometry has on behavior can be explained by channel biophysics. The majority of 
AMPA receptors contain GluA2 subunits and are impermeable to $\mathrm{Ca}^{2+}$. On the other hand, GluA2-lacking AMPA receptors, predominantly formed by GluA1 homomers, conduct $\mathrm{Ca}^{2+}$ and are known as $\mathrm{Ca}^{2+}$-permeable AMPA receptors (CPARs; CullCandy et al., 2006; Liu and Zukin, 2007). In addition to their ability to allow $\mathrm{Ca}^{2+}$-mediated intracellular signaling, CPARs also display inward rectification and have higher channel conductance than GluA2-containing receptors. These unique properties allow CPARs to regulate synaptic plasticity and thereby to influence behavior.

In this study, we establish a model of pain-induced depression and study the role of CPARs in the NAc in the modulation of depressive symptoms. We find that chronic pain increases GluA1 expression at NAc synapses, leading to the formation of CPARs. These CPARs, in turn, exert powerful control over depressive symptoms of chronic pain.

\section{Materials and Methods}

\section{Animals}

All procedures in this study were approved by the New York University School of Medicine Institutional Animal Care and Use Committee as consistent with the National Institutes of Health Guide for the Care and Use of Laboratory Animals (publication number 85-23) to ensure minimal animal use and discomfort. Male Sprague Dawley rats were purchased from Taconic Farms and kept in the New York University Langone Medical Center's Central Animal Facility and at Mispro Biotech Services Facility in Alexandria Center for Life Science, with controlled humidity, room temperature, and 12 h (6:30 A.M. to 6:30 P.M.) light/ dark cycle. Food and water were available ad libitum. Animals arrived to the animal facility at $250-300 \mathrm{~g}$ and were given on average $10 \mathrm{~d}$ to adjust to the new environment before the onset of any experiments.

\section{Spared nerve injury surgery}

The spared nerve injury (SNI) surgery was previously described in detail (Decosterd and Woolf, 2000; Wang et al., 2011). Briefly, under isoflurane anesthesia (1.5-2\%), the skin on the lateral surface of the right thigh of rat was incised and a section made through the biceps femoris muscle to expose three branches of the sciatic nerve: sural, common peroneal, and tibial nerves. The common peroneal and tibial nerves were tied with nonabsorbent 5-0 silk sutures at the point of trifurcation. The nerves were then cut distal to each knot, and $\sim 3-5 \mathrm{~mm}$ of the distal ends were removed. In sham surgeries (control), above nerves were dissected but not cut. Muscle layer was then sutured close, while skin was stapled. Staples were removed before behavioral testing.

\section{Cannula implantation and intracranial injections}

For cannula implantation, as described previously (Carr et al., 2010), rats were anesthetized with isofluorane (1.5-2\%). Rats were stereotaxically implanted with two 26 gauge guide cannulas (PlasticsOne) bilaterally in the NAc core with the following coordinates: $1.6 \mathrm{~mm}$ anterior to bregma, $2.9 \mathrm{~mm}$ lateral to the sagittal suture, tips angled $8^{\circ}$ toward the midline, 5.6 $\mathrm{mm}$ ventral to skull surface. Cannulas were held in place by dental acrylic and patency was maintained with occlusion stylets. For intracranial injections, solutions were loaded into two $30 \mathrm{~cm}$ lengths of PE-50 tubing attached at one end to $10 \mu \mathrm{l}$ Hamilton syringes filled with distilled water and at the other end to 33 gauge injector cannula, which extended 2.0 $\mathrm{mm}$ beyond the implanted guides. Injection of solution then delivered bilaterally $0.5 \mu \mathrm{l}$ of injection volume over a period of $100 \mathrm{~s}$. Injector cannulas were kept in place for another $60 \mathrm{~s}$ before removal from guides to allow diffusion of solution into the brain. Following the removal of injector cannulas from cannula guides, stylets were replaced and animals were subject to behavior tests. Behavior tests were done $15 \mathrm{~min}$ after intracranial injections. Following animal sacrifice, cryogenic brain sections were collected with thickness of $10 \mu \mathrm{m}$ using Microm HM525 cryostat and analyzed for cannula localization with histological staining; animals with improper cannula placements were excluded from the study.

\section{Drugs}

One-naphthyl acetyl spermine/ $\mathrm{N}$-acetyl-spermine (Naspm) and 2-pyrrolidinone were purchased from Sigma-Aldrich. Naspm was resuspended in saline to a concentration of $80 \mu \mathrm{g} / \mu \mathrm{l}$ and 2-pyrrolidinone was diluted in saline to a concentration of $100 \mathrm{ng} / \mu \mathrm{l}$. We injected $0.5 \mu \mathrm{l}$ in each side. Intracranial injections were given $\geq 14 \mathrm{~d}$ after SNI surgeries and were followed by behavioral tests. Equal volume of saline was injected as control.

\section{Subcellular fractionation and Western blotting}

Rats were anesthetized with isofluorane (1.5-2\%) and decapitated immediately. Brains were quickly removed and NAcs were collected on ice. The NAcs were dissected from 1.08-2.52 mm anterior to bregma, with average sample weight of $40 \mathrm{mg}$. Whole-cell and synaptosome fractions were prepared as described previously (Jordan et al., 2004; Restituito et al., 2011). To prepare whole-cell and synaptoneurosome fractions, NAc samples were homogenized in an ice-cold Solution A ( $0.32 \mathrm{~m}$ sucrose, 1 $\mathrm{mm} \mathrm{NaHCO}_{3}, 1 \mathrm{~mm} \mathrm{MgCl}, 0.5 \mathrm{~mm} \mathrm{CaCl}_{2}, 0.1 \mathrm{~mm} \mathrm{PMSF}$, and $1 \times \mathrm{Com}-$ plete Protease Inhibitors; Roche Applied Science). Homogenates were centrifuged at $4000 \mathrm{rpm}$ for $10 \mathrm{~min}$. The supernatant was collected and the pellet rehomogenized in Solution A and centrifuged again at 3000 $\mathrm{rpm}$ for $10 \mathrm{~min}$. Combined supernatants were subjected to a second centrifugation at $3000 \mathrm{rpm}$ for $10 \mathrm{~min}$. Supernatants were then spun at $14,000 \mathrm{rpm}$ for $30 \mathrm{~min}$. Pellet was resuspended in Solution B $(0.32 \mathrm{~m}$ sucrose, $1 \mathrm{~mm} \mathrm{NaHCO}_{3}$ ) and homogenized. Homogenate was layered on top of a $5 \mathrm{ml} 1 \mathrm{M}$ sucrose and $1.2 \mathrm{M}$ sucrose gradient and centrifuged at $30,000 \mathrm{rpm}$ for $2 \mathrm{~h}$. Purified synaptosomes were collected at the $1 \mathrm{~m}$ and $1.2 \mathrm{M}$ sucrose interface, suspended in Solution B and centrifuged at $40,000 \mathrm{rpm}$ for $45 \mathrm{~min}$. Synaptosomal pellets were resuspended in $25 \mathrm{~mm}$ TRIS with $4 \%$ SDS. Fractions were analyzed by Western blot on SDSPAGE gels as described previously (Jordan et al., 2004; Restituito et al., 2011). The following antibodies were used: GluA1 (1:1000; Millipore), phospho-Ser 845 GluA1 (1:1000; Millipore), GluA2 (1:1000; Millipore), and tubulin (1:30,000; Sigma-Aldrich).

To prepare cytosolic fractions, the resulting supernatant from the 30 min $14,000 \mathrm{rpm}$ spin was mixed with $2 \%$ deoxycholate to a $0.02 \%$ final concentration and kept at room temperature for $15 \mathrm{~min}$ before the addition of $100 \%$ trichloroacetic acid to get a $10 \%$ final concentration and spun at 14,000 rpm for $10 \mathrm{~min}$. The supernatant was discarded and the pellet washed with acetone and spun at 14,000 rpm for 5 min twice. Pellet was then dried by placing the tube on a heat block to dry off the acetone residue and analyzed by Western blot.

\section{Electrophysiology}

Fourteen days after SNI or sham, rats were deeply anesthetized with isofluorane (2\%) and decapitated immediately. Brains were quickly removed into dissection buffer, which consisted of the following (in $\mathrm{mm}$ ): 75 sucrose, $87 \mathrm{NaCl}, 2.5 \mathrm{KCl}, 1.25 \mathrm{NaH}_{2} \mathrm{PO}_{4}, 0.5 \mathrm{CaCl}_{2}, 7 \mathrm{MgCl}_{2} 6 \mathrm{H}_{2} \mathrm{O}$, $25 \mathrm{NaHCO}_{3}, 10$ dextrose, bubbled with $95 \% \mathrm{O}_{2} / 5 \% \mathrm{CO}_{2}, \mathrm{pH}$ 7.4. Coronal slices ( $300 \mu \mathrm{m}$ thick) containing the NAc were cut in ice-cold dissection buffer using a vibrotome (Leica, VT1200S) and then submerged in ACSF (in mm: $124 \mathrm{NaCl}, 2.5 \mathrm{KCl}, 1.25 \mathrm{NaH}_{2} \mathrm{PO}_{4}, 2.5 \mathrm{CaCl}_{2}, 1.5 \mathrm{MgSO}_{4} 7$ $\mathrm{H}_{2} \mathrm{O}, 26 \mathrm{NaHCO}_{3}$, and 10 dextrose) for $<30 \mathrm{~min}$; then kept in a slice preincubator at room temperature for at least $1 \mathrm{~h}$ to allow for recovery. Slices were transferred to the recording chamber and perfused $(2.0-2.5$ $\mathrm{ml} / \mathrm{min}$ ) with oxygenated ACSF at $33-35^{\circ} \mathrm{C}$ containing $50 \mu \mathrm{m}$ APV and $50 \mu \mathrm{m}$ picrotoxin to isolate EPSCs. Somatic whole-cell recordings were made from core region medium spiny neurons (MSNs) in voltage clamp with a Multiclamp 700B amplifier (Molecular Devices) using infrareddifferential interference contrast video microscopy. Patch pipettes (4-6 $\mathrm{M} \Omega$ ) were filled with intracellular solution (in mM: 125 Cs-gluconate, 2 CsCl, 5 TEA-Cl, 4 Mg-ATP, 0.3 GTP, 10 phosphocreatine, 10 HEPES, 0.5 EGTA, $100 \mu \mathrm{m}$ spermine, and 3.5 QX-314). Data were filtered at $2 \mathrm{kHz}$, digitized at $10 \mathrm{kHz}$, and analyzed with Clampfit 10 (Molecular Devices). Extracellular stimulation $(0.01-1 \mathrm{~ms}, 5-150 \mu \mathrm{A}, 0.2 \mathrm{~Hz})$ was applied with a small glass bipolar electrode $0.05-0.5 \mathrm{~mm}$ from the recording electrode. After $\sim 10 \mathrm{~min}$ of baseline recording, a solution containing Naspm $(200 \mu \mathrm{M})$ was perfused for $10 \mathrm{~min}$. Changes in EPSC amplitude were measured before and after drug application at holding potentials of -70 , 
$-50,-30,0,+20,+40$, and $+60 \mathrm{mV}$. The rectification index $\left(i_{\mathrm{r}}\right)$ was calculated by correcting any potential shifts in reversal potential and computed from the following equation: $i_{\mathrm{r}}=\left(I_{-70} / 70\right) /\left(I_{+40} / 40\right)$, where $I_{-70}$ and $I_{+40}$ are the EPSC amplitudes recorded at -70 and $+40 \mathrm{mV}$, respectively (Conrad et al., 2008).

\section{Animal behavioral tests}

Mechanical hypersensitivity test. A traditional Dixon up-down method with von Frey filaments was used to measure mechanical hypersensitivity as described previously (Chaplan et al., 1994; Bourquin et al., 2006; Wang et al., 2011). In brief, rats were individually placed into Plexiglas chambers over a mesh table and acclimated for 20 min before the onset of examination. Beginning with $2.55 \mathrm{~g}$, von Frey filaments in a set with logarithmically incremental stiffness $(0.45,0.75,1.20,2.55,4.40,6.10$, $10.50,15.10 \mathrm{~g}$ ) were applied to the lateral one-third of right paws (in the distribution of the sural nerve) of rats. A $50 \%$ withdrawal threshold was calculated as described previously (Wang et al., 2011).

Cold hypersensitivity test. Animals were individually placed into Plexiglas chambers as above and acclimated for $20 \mathrm{~min}$. A drop of acetone was applied to the lateral plantar surface of the paws (in the distribution of the sural nerve). As previously described (Hao et al., 1999; Jørum et al., 2003; Wang et al., 2011), the following scoring system was applied: 0, no visible response or startle response lasting $<0.5 \mathrm{~s} ; 1$, paw withdrawal lasting $<5$ s; 2, withdrawal lasting 5-10 s, with or without licking of the paws; 3 , prolonged repetitive withdrawal lasting $>10 \mathrm{~s}$. Acetone was applied five times to each paw, and an average score was calculated. Cold hypersensitivity tests were typically done after mechanical allodynia tests on the same day, and observers were blinded to the test conditions.

Sucrose preference test. As described previously (Wang et al., 2011), animals were acclimated to the test room for $\geq 20 \mathrm{~min}$. Two bottles $(1 \%$ sucrose solution vs water) were presented to each animal for $30 \mathrm{~min}$, and then the bottles were switched to the opposite side, and the test continued for an additional $30 \mathrm{~min}$. At the end of each test, sucrose preference was calculated as volume of sucrose consumed divided by total liquid consumption for each rat. Rats were allowed to eat and drink ad libitum prior to the test.

Forced swim test. As described previously (Wang et al., 2011), animals were acclimated to the test room. On the first session of the test, each animal was placed for $15 \mathrm{~min}$ into a standard clear Porsolt chamber with water at $25^{\circ} \mathrm{C}$ filled to $25 \mathrm{~cm}$. Afterward, the animal was taken out of the chamber, dried, and put back in its home cage. Twenty-four hours later, the animal was placed into the Porsolt chamber again under the same conditions for $5 \mathrm{~min}$. The second session was recorded and analyzed. Immobility was defined as a lack of movement of the hind paws lasting $>1 \mathrm{~s}$. Two independent observers, blinded to the test conditions, examined and graded the total time of immobility for each rat.

Locomotion activities. As described previously (Cabeza de Vaca and Carr, 1998), rats were acclimated in locomotor measurement chambers (Accuscan) before testing. On test days, locomotion activities were measured for a total of $30 \mathrm{~min}$. Distance traveled was measured using the VersaMax System (Accuscan), which monitored animal activity via a grid of $16 \times 16$ infrared light beams that traverse the animal cage $(42 \times 42 \times$ $30 \mathrm{~cm}$ ) front to back and left to right. Information about beam status, scanned at a rate of 100 times per second, was stored to disk. Activity was expressed as ambulatory distance measured in number of beam breaks during 10 different $3 \mathrm{~min}$ bins in a $30 \mathrm{~min}$ session.

\section{Statistics}

For Western blots, unpaired two-tailed Student's $t$ tests were used to analyze the protein levels in SNI-treated versus sham-treated rats. For electrophysiology experiments, differences in rectification indices between SNI and sham groups, as well as changes in EPSCs in the presence of Naspm for either group, were analyzed using two-tailed Student's $t$ tests. The results of behavioral experiments were given as mean \pm SEM. For mechanical and cold hypersensitivity, a two-way ANOVA with repeated-measures and post hoc multiple pairwise comparison Bonferroni tests was used to compare the $50 \%$ withdrawal threshold of SNItreated and sham-treated rats. For the sucrose preference test (SPT), a two-tailed Student's $t$ test was used to compare SNI-operated and sham- operated rats, and a two-way ANOVA with post hoc Bonferroni tests was used to compare Naspm or 2-pyrrolidinone versus saline treatment in sham and SNI groups. For the forced swim test (FST), Student's $t$ test was used to compare the performances of sham and SNI groups, and a twoway ANOVA with post hoc Bonferroni tests was used to compare Naspm or 2-pyrrolidinone versus saline treatment in sham and SNI groups. A two-way ANOVA with repeated-measures and post hoc multiple pairwise comparison Bonferroni tests was used to compare the locomotor activities for SNI-operated versus sham-operated rats and for rats receiving Naspm or 2-pyrrolidinone versus saline over $30 \mathrm{~min}$. For all tests, a $p$ value $<0.05$ was considered statistically significant. All data were analyzed using Prism Version 5 software (GraphPad).

\section{Results}

\section{Chronic pain leads to depression-like behaviors}

To study the regulation of pain-induced depression, we used the SNI model, a peripheral nerve injury model for chronic neuropathic pain (Decosterd and Woolf, 2000; Wang et al., 2011). We surgically resected two of three branches of the sciatic nerve, causing permanent nerve injury and neuropathic pain (Decosterd and Woolf, 2000). Three days after SNI, rats experienced abnormal hypersensitivity to mechanical and cold stimuli (Fig. $1 A, p<0.01$; Fig. $1 B, p<0.001$ ), classic sensory indices for pain. Sensory hypersensitivity after SNI was chronic, persisting for at least $14 \mathrm{~d}$ ( $p<0.01$ and $<0.001$ for mechanical and cold hypersensitivity, respectively; Fig. $1 A, B)$, as has been observed previously (Decosterd and Woolf, 2000; Wang et al., 2011). In contrast, control rats that underwent sham operation did not show this sensory hypersensitivity (Fig. $1 A, B$ ).

Next, we examined the depressive symptoms associated with pain. Recently, we and others have observed depression-like behaviors in rats with chronic pain (Gonçalves et al., 2008; Hu et al., 2009; Wang et al., 2011; Kim et al., 2012). Here, to demonstrate depression-like behaviors induced by chronic neuropathic pain, we used the sucrose preference test (SPT), a standard test for measuring anhedonia, a defining feature of depression (Nestler and Hyman, 2010). SNI-operated rats, compared with control, showed decreased preference for sucrose (Fig. $1 C, p<0.01$ ). The SNI group consumed less volume of sucrose solution than control (Fig. $1 D, p<0.01$ ). While the SNI group drank more water during this test, this difference is not statistically significant (Fig. $1 E, p>0.05)$. Most importantly, there was no statistically significant difference between the sham and SNI groups in the total fluid volume consumption (Fig. $1 F, p>0.05$ ), indicating that SNI did not alter the ability of rats to drink fluid. The rats were allowed to eat ad libitum, but to further rule out the possibility that changes in metabolism played a role in the SPT, we measured the weight of these two groups (Fig. 1I). We did not observe any difference in weight before or after the induction of chronic pain, indicating no gross difference in metabolism between SNI and sham groups. Thus, these data suggest that, according to standard interpretation of the SPT, the SNI group, in comparison with the sham group, was less able to perceive the hedonic value of the sucrose solution and experienced anhedonia, a key feature of depression.

To confirm our finding on the SPT, we also used the forced swim test (FST), another standard test in rats to assess depression-like behaviors. Increased immobility on the FST has been used as a test for behavioral despair, a salient feature of depression. Numerous studies have demonstrated clinically relevant pharmacological validity in this test (Nestler and Hyman, 2010). In our study, compared with control rats, SNI-treated rats showed increased immobility (Fig. $1 G, p<0.05$ ). We have previously shown that this increased immobility on FST is reflective 


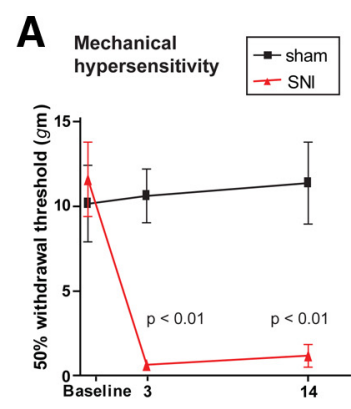

Days after surgery


B
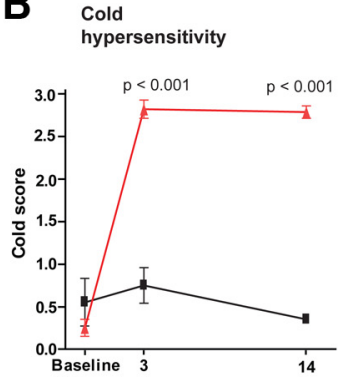

Days after surgery

\section{G}

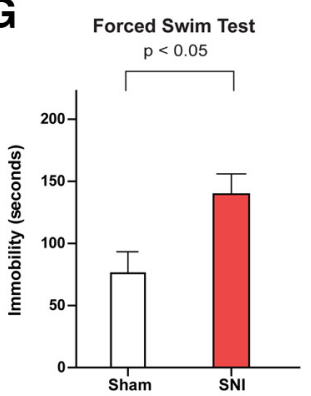

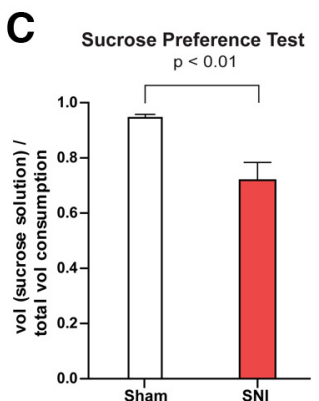

H

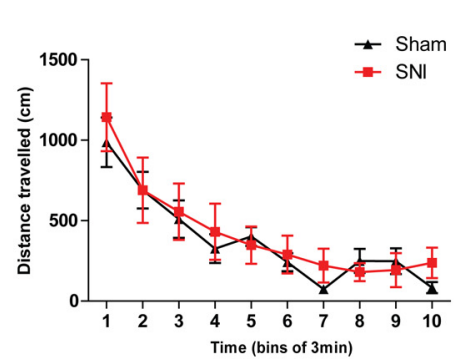

D

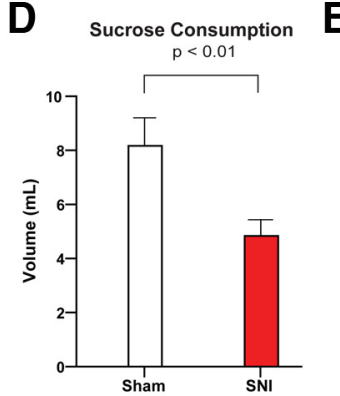

E

Water Consumption

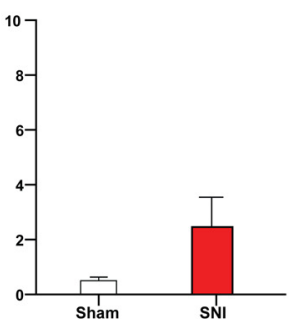

I

Weight Changes



Figure 1. SNI causes depression-like behaviors. $A$, SNI-operated rats developed mechanical hypersensitivity after surgery, compared with sham-operated rats. Two-way ANOVA with Bonferroni post-test. $n=6, p<0.01$. B, Animals after SNI developed cold hypersensitivity. Two-way ANOVA. $n=6, p<0.001$. C, SNI decreased sucrose preference on the SPT. Student's t test, $n=11$ (sham), 15 (SNI), $p<0.01$. D, SNI decreased sucrose consumption on the SPT. $p<0.01$. E, SNI caused no changes in water consumption on the SPT. $p>0.05$. F, SNI caused no changes in total fluid consumption on the SPT. $p>0.05$. G, SNl increased immobility on the FST. Student's $t$ test, $n=10, p<0.05$. H, SNI caused no changes in locomotion. Two-way ANOVA with repeated measures, $n=6, p>0.05$. I, Chronic pain did not result in changes in weight. Two-way ANOVA, $n=15, p>0.05$. Error bars show mean and SEM.

of depression-like behaviors, rather than of changes in locomotion (Wang et al., 2011). Here, to further rule out the possibility that this immobility was caused by locomotor deficits secondary to peripheral neuropathy or by pain associated with movement, we performed locomotion tests on SNI-treated rats. SNI-treated rats, compared with sham-treated rats, did not display a change on the locomotion test over $30 \mathrm{~min}$ (Fig. $1 \mathrm{H}$ ), and thus these rats were unlikely to have overt locomotor deficits that prevented them from swimming for $5 \mathrm{~min}$. Increased immobility on FST, therefore, more likely reflected depression-like behaviors exhibited by these animals in chronic pain (Nestler and Hyman, 2010). As SPT and FST are independent tests for depression-like behaviors in rats, the performances of SNI-treated animals demonstrate that this model effectively represents pain-induced depression in rats.

\section{Chronic pain selectively increases GluA1 expression at NAc synapses}

To understand how chronic pain regulates AMPA receptor signaling in the NAc, we measured the levels of AMPA receptor subunits from synaptoneurosome preparations of NAc neurons $14 \mathrm{~d}$ after SNI or sham surgery. Over $90 \%$ of neurons in the NAc are median spiny neurons (MSNs), and synaptoneurosome preparations reflect synaptic fractions of these neurons. GluA1 and GluA2 are predominantly expressed in the MSNs. Here, to our surprise, we found a substantial $(>80 \%)$ increase in the GluA1 subunit levels of SNI-treated animals, compared with sham control (Fig. $2 A, p<0.05$ ). The level of GluA2 subunits, in contrast, remained unchanged (Fig. $2 A$ ).

Increased receptor subunit expression may be the result of increased exocytotic trafficking or synthesis, or decreased endocytosis or degradation. We did not observe any changes in GluA1 levels in either the cytosolic or the whole-cell fraction of the
MSNs after SNI (Fig. 2A, B, $p>0.05$ ), which suggested that this increase in GluA1 subunits occurred locally at or near synapses. To assess the role of trafficking, we examined phosphorylation of GluA1 Ser845, previously shown to be a required step for GluA1 accumulation at the cell surface (Serulle et al., 2007). We found that phospho-Ser845 was increased by $90 \%$ (Fig. $2 C, p<0.05$ ) in the synaptoneurosomes after SNI. This level of increase was comparable to the increase in synaptosomal levels of GluA1 (Fig. 2A), suggesting that this trafficking mechanism was conserved in the chronic pain state and could have contributed to the accumulation of GluA1 subunits at the synapses.

To verify the specificity of AMPA receptor subunit changes that we observed, we also measured GluA1 and GluA2 levels in the hippocampus, cerebellum, and amygdala as controls. In contrast to what we observed in the NAc, GluAl levels were not altered after SNI in the hippocampus, cerebellum, and amygdala (Fig. 2D-F, $p>0.05$ ). GluA2 subunit levels were also not significantly changed in these brain regions (Fig. $2 D-F, p>0.05$ ). Thus, the selective increase in GluA1 AMPA receptor subunits is relatively specific to the NAc in the chronic pain state.

\section{Chronic neuropathic pain causes the formation of CPARs at the synapses of the MSNs}

An increase in the synaptic level of GluA1 subunits, without a concurrent change in GluA2, suggests an increase in the overall number of AMPA receptors at synapses. In particular, a selective increase in GluA1 subunits may lead to the formation of GluA1 homomers, which are GluA2-lacking AMPA receptors. GluA2lacking receptors display unique biophysical properties including $\mathrm{Ca}^{2+}$ permeability, high single-unit conductance, and inward rectification due to block by endogenous polyamines at positive voltages (Cull-Candy et al., 2006; Isaac et al., 2007; Liu and Zukin, 2007). Due to their $\mathrm{Ca}^{2+}$ permeability, GluA2-lacking receptors 
A

Nucleus Accumbens (NAc)

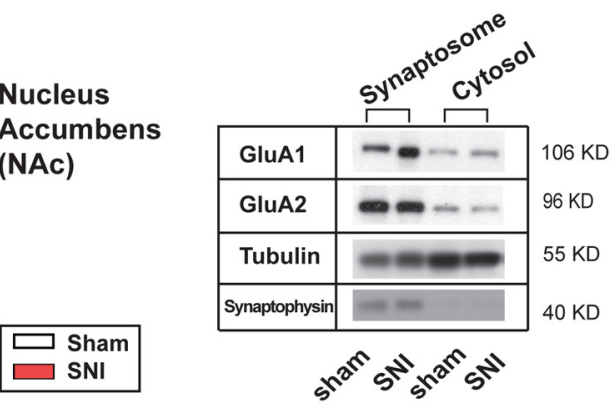

Cytosol

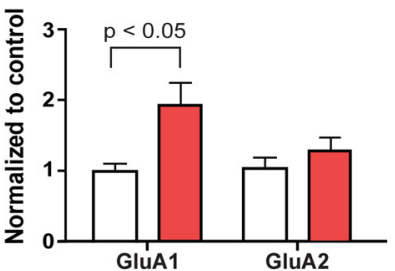

D
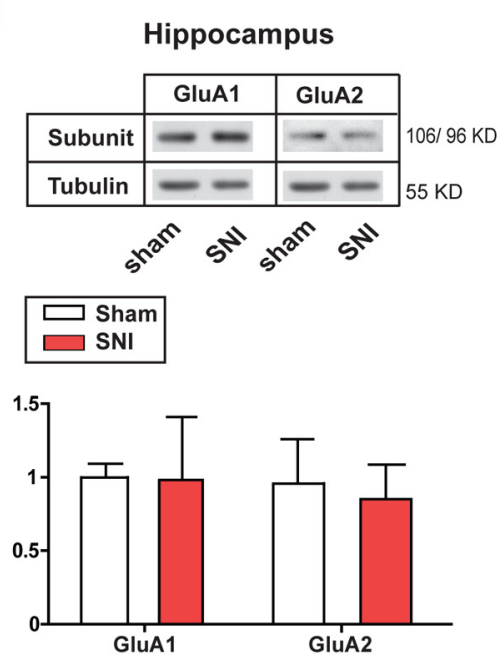

\section{(n)}

B

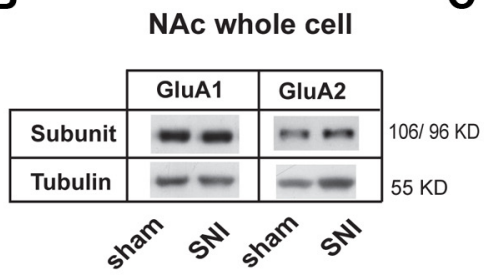

Whole Cell

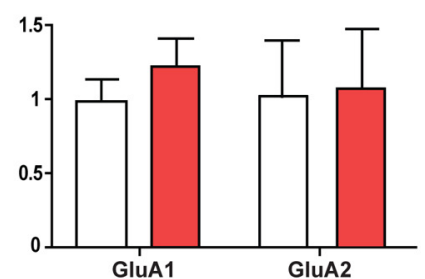

NAc synaptoneurosome

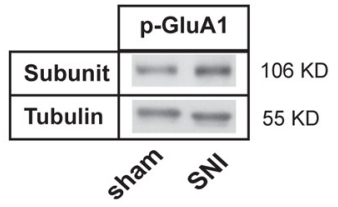

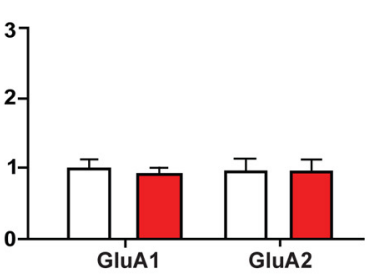

E
F
Synaptoneurosome



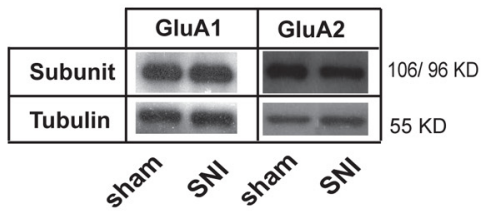

Figure 2. SNI selectively increases GluA1 levels at synapses of the NAc. $\boldsymbol{A}$, SNI resulted in an increase in GluA1 subunits in the synaptoneurosomes of NAc. Student's $t$ test, $n=6, p<0.05$. SNI caused no changes in GluA2 subunits. $n=6, p>0.05$. SNI did not cause changes in GluA1 or GluA2 levels in the cytosolic fraction. $n=6, p>0.05$. $\boldsymbol{B}$, SNI caused no changes in levels of GluA1 or GluA2 in whole-cell fractions of NAc. $n=9$ (GluA1), $p>0.05, n=6$ (GluA2), $p>0.05$. C, SNI caused an increase in pSer845-GluA1 levels in the synaptoneurosomes of NAc. $n=6, p<0.05$. D, SNI caused no changes in levels of GluA1 or GluA2 subunits in the synaptoneurosomes of hippocampus. $n=5$ (GluA1), $p>0.05, n=4$ (GluA2), $p>0.05$. E, SNI caused no changes in levels of GluA1 or GluA2 subunits in the synaptoneurosomes of cerebellum. $n=6$ (GluA1), $p>0.05, n=12$ (GluA2), $p>0.05$. F, SNI caused no changes in levels of GluA1 or GluA2 subunits in the synaptoneurosomes of amygdala. $n=6$ (GluA1), $p>0.05, n=5$ (GluA2), $p>0.05$. Data were normalized to values in the sham group. Error bars show mean and SEM.

are also known as $\mathrm{Ca}^{2+}$-permeable AMPA receptors, or CPARs. CPARs are known to augment synaptic transmission (CullCandy et al., 2006; Isaac et al., 2007; Liu and Zukin, 2007). To test the formation of CPARs in the chronic pain state, we performed whole-cell patch-clamp recordings from neurons in brain slices of the NAc $14 \mathrm{~d}$ after SNI or sham surgery (Fig. 3). Experimentally, EPSCs conducted by CPARs can be tested by inward rectification and sensitivity to Naspm. In the voltage-clamp recording, inward rectification is characterized by nonlinearity in current-voltage $(I-V)$ relationship, where current amplitude measured at more positive potentials is decreased relative to current measured at negative voltage potentials. Meanwhile, Naspm is a well known highly selective blocker of GluA2-lacking AMPA receptors (Cull-Candy et al., 2006).

We identified MSNs visually in the NAc core region, and recorded evoked EPSCs from these neurons (Fig. 3). EPSCs from neurons in SNI-treated animals displayed an inward rectifica- tion, as indicated by nonlinearity in the $I-V$ relationship (Fig. $3 B, C)$. This inward rectification was minimally expressed, however, in neurons from sham-operated rats (Fig. $3 A, C$ ). We then calculated the rectification index (RI) using $I-V$ relationships for sham-treated and SNI-treated animals (Conrad et al., 2008). When we compared the RIs for these two groups, we found a substantial difference ( $40 \%$ increase in the SNI group; Fig. $3 D$, $p<0.01)$. These data suggest that SNI-treated rats, compared with sham control, exhibited the signature of CPAR-mediated currents in their MSNs.

To further confirm this finding of CPAR currents in SNItreated animals, we examined the sensitivity of EPSCs to Naspm, in SNI-operated and sham-operated animals. We found that bath application of Naspm (10 $\mathrm{min})$ reduced the amplitudes of EPSCs in neurons recorded from the SNI group (Fig. $3 F$ ). When we compared EPSC amplitudes measured at $-70 \mathrm{mV}$ before and after Naspm treatment, we found Naspm reduced these currents 


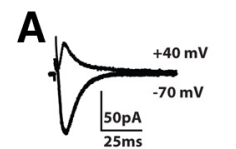

C
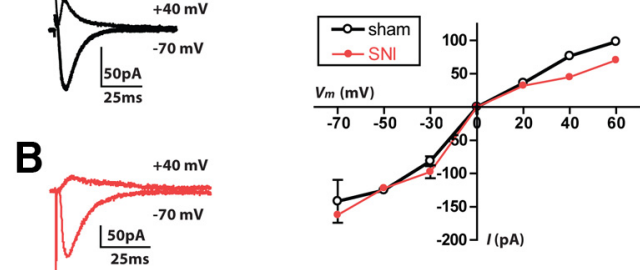

D

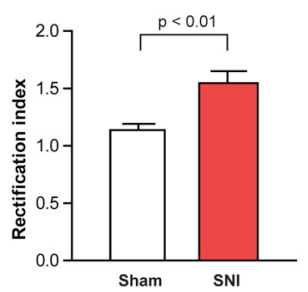

E

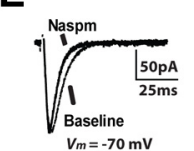

$\mathbf{F}$
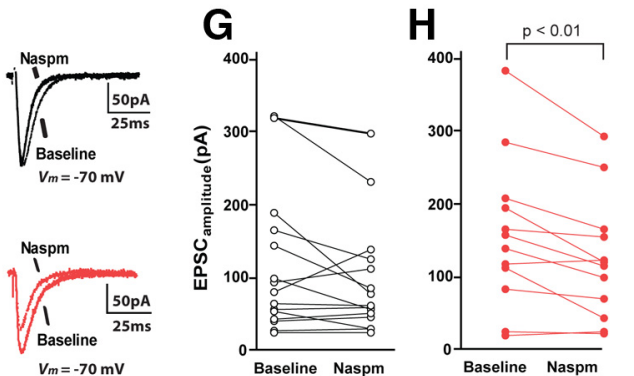

I



Figure 3. Chronic neuropathic pain causes the formation of CPARs in the NAc. $A-C$, Neurons from SNI-operated rats showed decreased EPSCs at depolarized voltages, compared with neurons from sham-operated rats. $A, B$, representative traces; $C$, cumulative $I-V$ relationship. $D$, EPSCs from SNI-operated rats showed increased rectification index. Student's $t$ test, $n=12-15$ neurons from five rats, $p<0.01$. $\boldsymbol{E}, \mathbf{G}$, Naspm had no effects on EPSCs in sham-operated rats. $\boldsymbol{E}$, Representative current traces for baseline versus Naspm treatment (10 min bath application) in a neuron from a sham-treated rat. $\mathbf{G}$, Evoked EPSCs before and after bath Naspm application. Student's $t$ test, $n=15$ neurons from five sham-treated rats, $p>0.05$. $\boldsymbol{F}, \boldsymbol{H}$, Naspm decreased EPSC amplitudes in SNI-treated rats. $\boldsymbol{F}$, Representative current traces for baseline versus Naspm treatment (10 min bath application) in a neuron from a SNI-treated rat. $\boldsymbol{H}$, Evoked EPSCs before and after bath Naspm application showed a reduction in current amplitudes. Student's $t$ test, $n=12$ neurons from five SNI-treated rats, $p<0.01$. I, Schematic of the NAc showing EP recording sites in red circles. Recordings were done $14 \mathrm{~d}$ after SNI or sham surgery. Error bars show mean and SEM.

by $20 \%$ (Fig. $3 H, p<0.01$, SEM 7\%). A change in current amplitude with Naspm, however, was not seen in neurons recorded from sham-operated animals (Fig. $3 E, G, p>0.05$, average difference of 7\%, SEM of 9\%). Thus, these physiology data confirm our biochemical findings of increased synaptic GluA1 levels and demonstrate that functional CPARs are indeed formed specifically at the synapses of MSNs in response to chronic neuropathic pain.

\section{CPARs in the NAc regulate}

depression-like behaviors associated with chronic pain

To test the behavioral function of these highly specialized glutamate receptors in pain, we injected Naspm into the NAc to block CPARs in SNI-treated rats (Fig. $4 A, B$ ), and then performed assays for both sensory and depressive features of pain. Transmission through NAc has been shown to play a role in analgesia (Gear et al., 1999; Magnusson and Martin, 2002). We were surprised to find, however, that Naspm did not alter mechanical or cold hypersensitivity after SNI (Fig. $4 C, D, p>0.05$ ). These hypersensitivity tests are commonly used in both animal and human studies to indicate nociception, or the transmission of the sensory pain signal. The lack of Naspm effect on nociception suggests that while CPARs in the NAc are formed in response to chronic pain, their role is not necessarily to regulate the sensory transmission of the pain signal.

Glutamate signaling has recently been suggested to play an important role in depression (Hashimoto, 2009; Skolnick et al., 2009; Sanacora et al., 2012), and pharmacologic agents that increase transmission through AMPA receptors have been shown to have antidepressant effects (Skolnick, 2008; Machado-Vieira et al., 2009; Li et al., 2010a; Wang et al., 2011). Therefore, we next examined the effect of blocking CPARs in the NAc on depressionlike behaviors induced by chronic neuropathic pain using the
SPT and FST. Sucrose preference was decreased in SNI-operated rats compared with sham-treated rats (Fig. 1C). When we measured sucrose preference in the presence of Naspm treatment (vs saline) in SNI-treated rats, however, we found that it was substantially further reduced (Fig. $4 E, p<0.05$ ). This anhedonic effect of Naspm was not seen, however, in sham-operated rats (Fig. $4 E, p>0.05$ ), which lacked CPAR expression (Fig. $3 E, G)$. Thus, blocking CPARs in the NAc worsened anhedonia, a key feature of depression-like behaviors, specifically in those rats that experienced chronic pain.

Next, we further examined depressionlike behaviors associated with neuropathic pain using the FST. We found that Naspm produced a striking increase in the immobility index on the FST in SNI-operated rats (Fig. $4 F, p<0.05$ ), but not in control (sham-operated) rats (Fig. $4 F, p>0.05$ ). These results indicate that CPAR block worsened behavioral despair (as suggested by immobility on the FST) specifically in rats with chronic pain. To further verify that this effect of Naspm on immobility is specific for depression-like behaviors, rather than changes in locomotor activities, we then measured locomotion after Naspm application. Here, we found that Naspm had no effect on SNI-treated animals (Fig. $4 G, p>0.05$ ).

Thus, while CPAR block in the NAc did not alter sensory symptoms of pain, it worsened depression-like behaviors associated with chronic pain, as shown by worse performances in the SPT and FST. These results suggest that, in vivo, CPARs are formed to provide a protective function against the depressive symptoms of pain, possibly as an adaptive mechanism, and that Naspm, by blocking CPARs, removed this protective antidepressant function.

\section{AMPA potentiator relieves pain-induced depression}

The finding that blocking CPARs increases pain-induced depression suggests the intriguing possibility that pharmacological enhancement of this receptor function may reduce depression-like behaviors in SNI-treated rats. AMPA potentiators are a class of compounds that increase AMPA receptor currents by slowing deactivation of open channels (Jin et al., 2005; Lynch and Gall, 2006; Skolnick, 2008). 2-pyrrolidinone is a well known AMPA potentiator that has been shown to increase the currents of GluR2-lacking receptors (Ito et al., 1990; Nishizaki and Matsumura, 2002; Jin et al., 2005). As there is an increase in CPARs in the pain state, we expect that 2-pyrrolidinone, by enhancing CPAR currents, should relieve pain-induced depression. When we administered 2-pyrrolidinone into the NAc in rats with chronic pain (Fig. $5 A, B$ ), sensory hypersensitivity was not significantly altered in SNI-treated rats (Fig. $5 D, E, p>0.05$ ), suggesting that augmenting CPARs is not sufficient to alter the sensory transmission of pain. 2-pyrrolidinone also did not cause gross motor changes (Fig. $5 C, p>0.05$ ). The depression-like behavior associated with chronic pain, however, was significantly reduced with 2-pyrrolidinone treatment, as shown by a significant improvement in sucrose preference (Fig. $5 F, p<0.05$ ). To further 
A

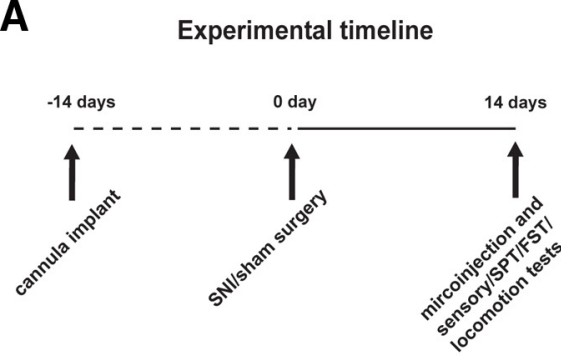

B

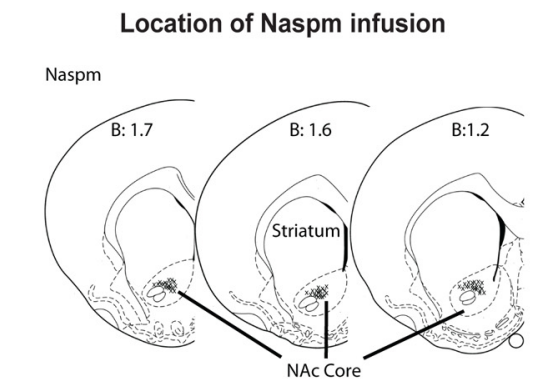

F Forced Swim Test

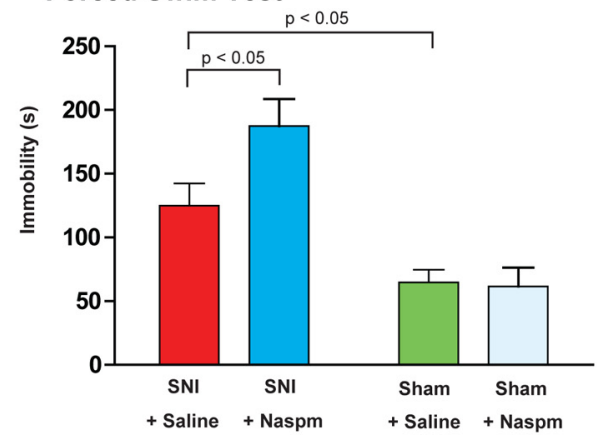

C

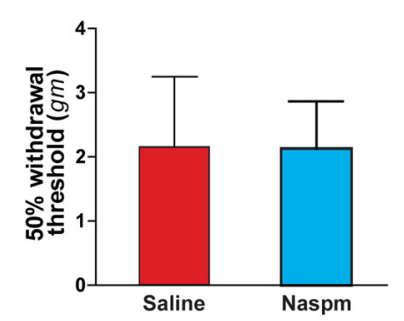

D Cold hypersensitivity

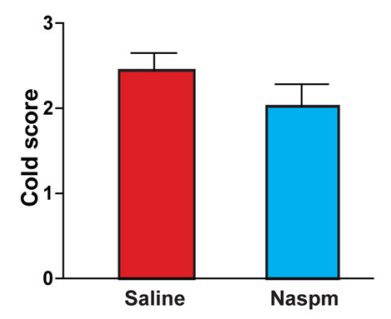

E Sucrose Preference Test

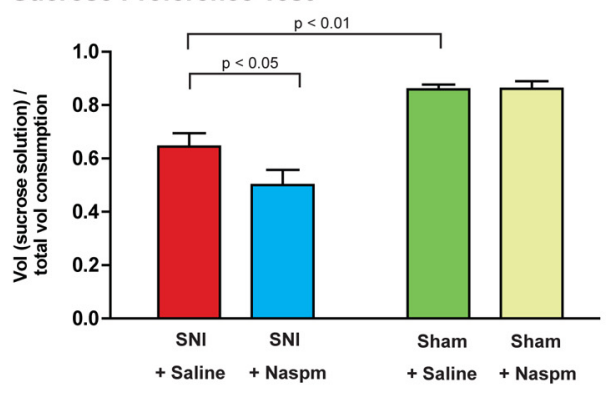

G

Locomotion

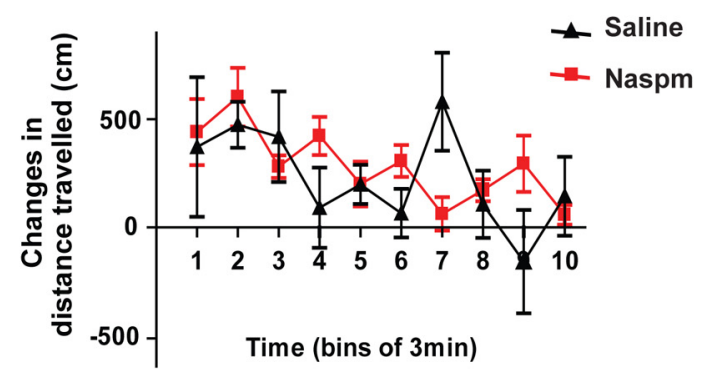

Figure 4. CPARs in the NAc protect against depression-like behaviors induced by chronic pain. $A$, Experimental paradigm. $B$, Schematic showing tip of the injectors in the NAc. $C$, Naspm infusion into the NAc did not change mechanical hypersensitivity in SNI-operated rats. Student's t test, $n=9, p>0.05$. D, Naspm did not change cold hypersensitivity in SNI-operated rats. $n=9, p>0.05$. $E$, Naspm in the NAc reduced sucrose preference in SNI-treated rats, but it had no effects on the sucrose preference of sham-treated rats. Two-way ANOVA with Bonferroni post-test. $n=11, p<$ 0.05. $\boldsymbol{F}$, Naspm in the NAc increased immobility in SNI-treated rats, but it did not alter immobility in sham-treated rats. Two-way ANOVA with Bonferroni post-test. $n=10-11, p<0.05 . \mathbf{G}$, Naspm did not alter locomotion in SNI-operated rats. Two-way ANOVA, $n=4-7, p>0.05$. Error bars show mean and SEM.

confirm the antidepressant effect of this AMPA potentiator in the NAc, we also measured immobility on the FST after administration of 2-pyrrolidinone. We observed a dramatic improvement in the immobility index as well (Fig. 5G, $p<0.05$ ). These results suggest that CPARs, which are upregulated in the NAc with the development of chronic pain, can be positively modulated by AMPA potentiators to reduce the depressive symptoms of pain. These data on 2-pyrrolidinone complement our data on Naspm (Fig. 4), and demonstrate that CPARs in the NAc can function as a molecular switch to allow bidirectional regulation of the depressive symptoms of pain.

\section{Discussion}

In this study, we find that chronic pain induces depressive behaviors in rats and also increases the synaptic level of GluA1 AMPA receptor subunits, leading to the formation of CPARs. Blockade of these CPARs worsens depressive symptoms, while potentiators ameliorate symptoms, suggesting that CPARs function to constrain the depressive symptoms of pain.

While imaging studies have identified the NAc as a brain region involved in chronic pain (Becerra and Borsook, 2008; Geha et al., 2008; Baliki et al., 2010, 2012), molecular changes occurring at the synapses within the NAc remain incompletely understood. Our study contributes to this understanding by providing direct evidence for pain-induced AMPA receptor changes at MSN synapses. This work complements previous studies demonstrating the roles, within the NAc, of opioid signaling in placebo effects, and dopamine signaling in descending inhibition, stress-induced hyperalgesia, and negative reinforcement from pain relief (Gear et al., 1999; Scott et al., 2008; Mickey et al., 2012; Navratilova et al., 2012). Together, these findings suggest that glutamate, dopamine, and opioid pathways all operate in the NAc to modulate the pain experience.

Our finding that pain increases GluA2-lacking AMPA receptors is compatible with established literature on the induction of these receptors by rewarding or aversive stimuli. Unlike GluA2 subunits, which are constitutively trafficked to the synapse, synaptic incorporation of GluA1 subunits requires sequential phosphorylation at Ser 845 and Ser 818 of GluA1 through a highly regulated molecular pathway (Esteban et al., 2003; Sun et al., 2005; Boehm et al., 2006; Serulle et al., 2007). Thus, GluA2lacking receptors have only been found under unique behavioral conditions, such as repeated consumption of cocaine or sucrose, 
A

Experimental timeline

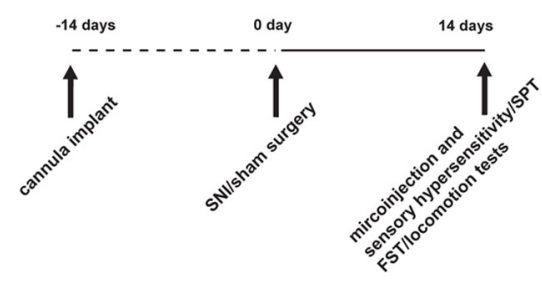

D Mechanical hypersensitivity

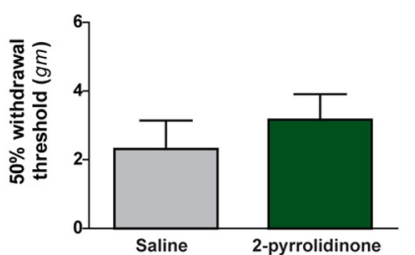

E Cold hypersensitivity

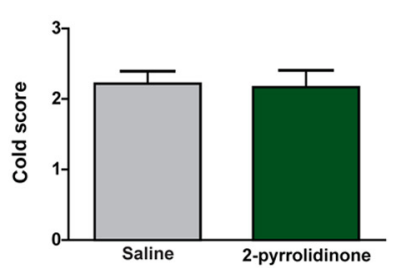

B

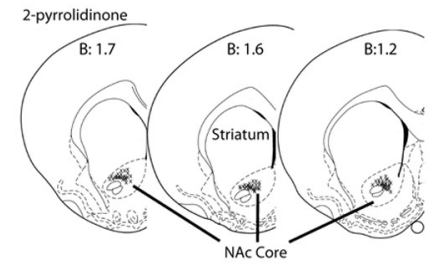

C Locomotion

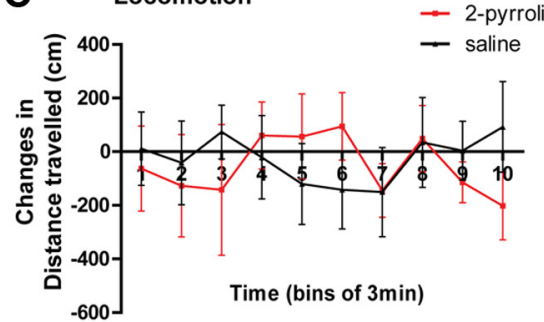

$F$

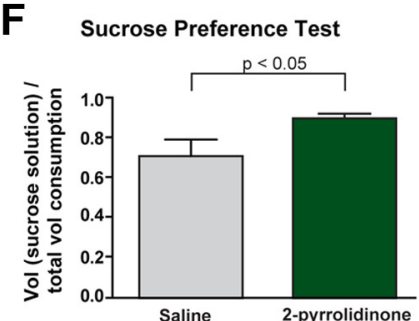

G

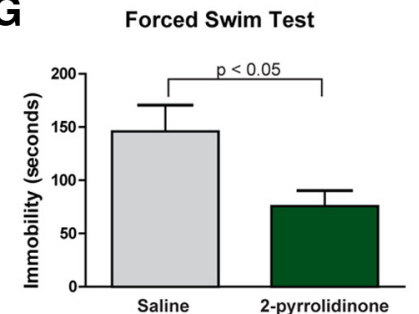

Figure 5. Potentiating CPARs abolishes depression-like behaviors induced by chronic pain. $\boldsymbol{A}$, Experimental paradigm. $\boldsymbol{B}$, Schematic showing tip of the injectors in the NAc. $\boldsymbol{C}$, Two-pyrrolidinone did not alter locomotion in SNI-operated rats. Two-way ANOVA, $n=5, p>0.05$. D, No changes in mechanical hypersensitivity was seen after 2-pyrrolidinone infusion into the NAc of SNI-treated rats. Student's $t$ test, $n=11-12, p>0.05$. E, Two-pyrrolidinone in the NAc had no effects on cold hypersensitivity in SNI-treated rats. $n=12, p>0.05$. $\boldsymbol{F}$, Two-pyrrolidinone in the NAc increased sucrose preference in SNI-treated rats. Student's $t$ test, $n=10-13, p<0.05$. G, Two-pyrrolidinone in the NAc decreased immobility in SNI-treated rats. $n=7, p<0.05$.

prolonged cocaine withdrawal, fear conditioning, and stress (Churchill et al., 1999; Argilli et al., 2008; Conrad et al., 2008; Clem and Huganir, 2010; Vialou et al., 2010; Lim et al., 2012; Tukey et al., 2013). Our data indicate that chronic pain also induces CPARs. In comparison with GluA2-containing receptors, CPARs can facilitate intracellular $\mathrm{Ca}^{2+}$ signaling, and they have higher single-unit conductance. These unique biophysical properties enable CPARs to play an important role at synapses, where they have been shown to induce long-term potentiation (LTP) as well as long-term depression (LTD), depending on the amount of $\mathrm{Ca}^{2+}$ influx and membrane potential (Cull-Candy et al., 2006; Isaac et al., 2007; Liu and Zukin, 2007). The ability of CPARs to regulate synaptic plasticity allows these receptors to govern a diverse set of behaviors in response to rewards, fear, and stress (Conrad et al., 2008; Clem and Huganir, 2010; Vialou et al., 2010; Lim et al., 2012; Tukey et al., 2013). Our finding that pain increases the formation of CPARs, therefore, provides an important synaptic basis for understanding the function of NAc in pain behaviors.

The current glutamate hypothesis for depression posits that alterations in glutamate signaling contribute to the regulation of depressive phenotype (Sanacora et al., 2012). There is accumulating evidence that central AMPA receptor subunit composition undergoes a complex pattern of change in animal models of depression. In a study using a social defeat model, Vialou et al. (2010) found that mice susceptible to depression display an increase in GluA1 and, more importantly, a decrease in GluA2 levels in the NAc, contributing to the formation of CPARs and depressive symptoms. In a chronic stress mouse model, meanwhile, Lim et al. (2012) reported that a decrease in synaptic GluA2 levels in D1-dopamine receptor expressing MSNs resulted in loss of GluA2-containing receptors, decreased transmission through AMPA receptors, and LTD. These two mouse studies on depression share similarities with our work in rats, as they also demonstrate the induction of GluA2-lacking AMPA receptors. However, our study shows that, in chronic pain, increased GluA1, not changes in GluA2 levels, contribute to the formation of CPARs within the NAc. Elsewhere in the brain, in the amygdala, PFC, and hippocampus, reduced levels of GluA1 have been found in rodents in chronic stress models (Yuen et al., 2012; Chandran et al., 2013; Duric et al., 2013). However, in our chronic pain model, we find no changes in GluA1/2 levels in the hippocampus and amygdala. These previous studies on AMPA receptors referred to above used various stress protocols to induce the depressive phenotype. Thus, we propose that chronic pain and stress are independent inducers of depression and, accordingly, they may elicit distinct AMPA receptor changes in the brain. More importantly, however, our study and these previous studies on depression are in agreement that alterations in AMPA receptor composition constitute an important element in the pathogenesis and regulation of the depressive phenotype, regardless of the cause of depression (Sanacora et al., 2012).

Our pharmacology data suggest that GluA1 upregulation may represent an adaptive mechanism to specifically constrain pain's depressive effects. These findings corroborate prior data that chronic antidepressant treatment selectively increases GluA1 levels in the NAc (Tan et al., 2006), and that GluA1 knock-out mice are vulnerable to depression (Chourbaji et al., 2008). More generally, this affective-emotional role for NAc in chronic pain is compatible with its established role in reward-seeking behaviors (Kalivas and Volkow, 2005; Fields, 2007; Conrad et al., 2008). Interestingly, in our study, neither Naspm nor 2-pyrrolidinone significantly alters sensory allodynia (Figs. $4 C, D, 5 D, E$ ), suggesting that in the NAc, CPARs, which represent a fraction of the total AMPA receptors, may not play a dominant role in nociception. These results do not mean, however, that the NAc has no role in nociception. In fact, studies have shown that the NAc mediates pain-induced analgesia through its projections to the rostroventral medulla (Gear et al., 1999; Magnusson and Martin, 2002). In this context, our results demonstrate that an additional role for NAc may be regulation of depressive symptoms of pain.

The increase in AMPA receptors in the NAc observed in our study has potential therapeutic implications. By reducing the desensitization of AMPA receptors, AMPA potentiators can am- 
plify glutamate transmission, and they have been shown to have antidepressant properties (Lynch and Gall, 2006; Skolnick, 2008). The increased number of AMPA receptors in pain states may provide an ideal milieu for the therapeutic benefit of AMPA potentiators.

The NAc contains core and shell regions. Both regions have been shown to play a role in depression (Muschamp et al., 2011; Chen et al., 2012; Lim et al., 2012). However, previous studies show that the core plays a dominant role in nociception (Gear et al., 1999; Magnusson and Martin, 2002). While core and shell are both primarily composed of MSNs, they differ in precise cellular morphology, neurochemistry, afferent projections, and efferent projections (Sesack and Grace, 2010). Physiologically, the core has been proposed to mediate cue-conditioned behavioral activation, such as reward-seeking. The shell, meanwhile, is thought to code the salience of a behavioral condition (Sesack and Grace, 2010). Our electrophysiology and behavior experiments are conducted in the core because of its established role in nociception and its ability to induce behavioral modification reflected in anhedonia and behavioral despair. The shell, meanwhile, can mediate the affective responsiveness to rewards and stress (Pliakas et al., 2001; Muschamp et al., 2011; Chen et al., 2012), and thus it may be expected to code the aversive quality of pain. Future investigation into synaptic changes in the shell should uncover its precise function in pain states.

Our study establishes the role of AMPA receptor signaling in the NAc in regulating pain-induced depression. Glutamate signaling in the PFC, amygdala, and hippocampus has been studied in the pathogenesis and regulation of depression (Pezawas et al., 2005; Ressler and Mayberg, 2007; MacQueen and Frodl, 2011; Yuen et al., 2012; Chandran et al., 2013; Duric et al., 2013). Altered synaptic activities within these regions have also been demonstrated to regulate cognitive and affective responses to pain (Ji et al., 2010; Li et al., 2010b; Ji and Neugebauer, 2011; Mutso et al., 2012; Cardoso-Cruz et al., 2013). Thus, our results on the role of NAc in pain-induced depression complement these findings. We do not observe any changes in GluA1/2 levels in the hippocampus and amygdala in our chronic pain model. However, our study is focused on AMPA receptors. Our data do not rule out the possibility that other signaling mechanisms, such as dopaminergic and opioidergic signaling in these regions, regulate pain-induced depression (Zubieta et al., 2001; Onozawa et al., 2011).

At the circuit level, the NAc receives glutamatergic inputs from the PFC, hippocampus, amygdala, and the thalamus and dopaminergic inputs from the VTA. It also projects back to these same regions (Sesack and Grace, 2010). Thus, our results suggest that the NAc functions as a node in an affective pain circuit, which also includes the PFC, amygdala, hippocampus, thalamus, and the VTA. A detailed mapping of this circuit would likely yield insight into how pain is processed centrally.

Together, our results highlight the synaptic activities in the NAc as an important regulator of pain-induced depression. Dynamic formation of CPARs regulates the depressive symptoms of pain, and thus therapeutics targeting CPAR activity in the NAc may improve mood and function in chronic pain patients.

\section{References}

Argilli E, Sibley DR, Malenka RC, England PM, Bonci A (2008) Mechanism and time course of cocaine-induced long-term potentiation in the ventral tegmental area. J Neurosci 28:9092-9100. CrossRef Medline

Baliki MN, Geha PY, Fields HL, Apkarian AV (2010) Predicting value of pain and analgesia: nucleus accumbens response to noxious stimuli changes in the presence of chronic pain. Neuron 66:149-160. CrossRef Medline
Baliki MN, Petre B, Torbey S, Herrmann KM, Huang L, Schnitzer TJ, Fields HL, Apkarian AV (2012) Corticostriatal functional connectivity predicts transition to chronic back pain. Nat Neurosci 15:1117-1119. CrossRef Medline

Bär KJ, Wagner G, Koschke M, Boettger S, Boettger MK, Schlösser R, Sauer H (2007) Increased prefrontal activation during pain perception in major depression. Biol Psychiatry 62:1281-1287. CrossRef Medline

Becerra L, Borsook D (2008) Signal valence in the nucleus accumbens to pain onset and offset. Eur J Pain 12:866-869. CrossRef Medline

Berton O, McClung CA, Dileone RJ, Krishnan V, Renthal W, Russo SJ, Graham D, Tsankova NM, Bolanos CA, Rios M, Monteggia LM, Self DW, Nestler EJ (2006) Essential role of BDNF in the mesolimbic dopamine pathway in social defeat stress. Science 311:864-868. CrossRef Medline

Boehm J, Kang MG, Johnson RC, Esteban J, Huganir RL, Malinow R (2006) Synaptic incorporation of AMPA receptors during LTP is controlled by a PKC phosphorylation site on GluR1. Neuron 51:213-225. CrossRef Medline

Bourquin AF, Süveges M, Pertin M, Gilliard N, Sardy S, Davison AC, Spahn DR, Decosterd I (2006) Assessment and analysis of mechanical allodynia-like behavior induced by spared nerve injury (SNI) in the mouse. Pain 122:14.e11-14. Medline

Cabeza de Vaca S, Carr KD (1998) Food restriction enhances the central rewarding effect of abused drugs. J Neurosci 18:7502-7510. Medline

Cardoso-Cruz H, Lima D, Galhardo V (2013) Impaired spatial memory performance in a rat model of neuropathic pain is associated with reduced hippocampus-prefrontal cortex connectivity. J Neurosci 33:2465-2480. CrossRef Medline

Carr KD, Chau LS, Cabeza de Vaca S, Gustafson K, Stouffer M, Tukey DS, Restituito S, Ziff EB (2010) AMPA receptor subunit GluR1 downstream of D-1 dopamine receptor stimulation in nucleus accumbens shell mediates increased drug reward magnitude in food-restricted rats. Neuroscience 165:1074-1086. CrossRef Medline

Chandran A, Iyo AH, Jernigan CS, Legutko B, Austin MC, Karolewicz B (2013) Reduced phosphorylation of the mTOR signaling pathway components in the amygdala of rats exposed to chronic stress. Prog Neuropsychopharmacol Biol Psychiatry 40:240-245. CrossRef Medline

Chaplan SR, Bach FW, Pogrel JW, Chung JM, Yaksh TL (1994) Quantitative assessment of tactile allodynia in the rat paw. J Neurosci Methods 53:5563. CrossRef Medline

Chen YW, Rada PV, Bützler BP, Leibowitz SF, Hoebel BG (2012) Corticotropin-releasing factor in the nucleus accumbens shell induces swim depression, anxiety, and anhedonia along with changes in local dopamine/acetylcholine balance. Neuroscience 206:155-166. CrossRef Medline

Chourbaji S, Vogt MA, Fumagalli F, Sohr R, Frasca A, Brandwein C, Hörtnagl H, Riva MA, Sprengel R, Gass P (2008) AMPA receptor subunit 1 (GluR-A) knock-out mice model the glutamate hypothesis of depression. FASEB J 22:3129-3134. CrossRef Medline

Churchill L, Swanson CJ, Urbina M, Kalivas PW (1999) Repeated cocaine alters glutamate receptor subunit levels in the nucleus accumbens and ventral tegmental area of rats that develop behavioral sensitization. J Neurochem 72:2397-2403. Medline

Clem RL, Huganir RL (2010) Calcium-permeable AMPA receptor dynamics mediate fear memory erasure. Science 330:1108-1112. CrossRef Medline

Conrad KL, Tseng KY, Uejima JL, Reimers JM, Heng LJ, Shaham Y, Marinelli M, Wolf ME (2008) Formation of accumbens GluR2-lacking AMPA receptors mediates incubation of cocaine craving. Nature 454:118-121. CrossRef Medline

Cull-Candy S, Kelly L, Farrant M (2006) Regulation of Ca2+-permeable AMPA receptors: synaptic plasticity and beyond. Curr Opin Neurobiol 16:288-297. CrossRef Medline

Decosterd I, Woolf CJ (2000) Spared nerve injury: an animal model of persistent peripheral neuropathic pain. Pain 87:149-158. CrossRef Medline

Duric V, Banasr M, Stockmeier CA, Simen AA, Newton SS, Overholser JC, Jurjus GJ, Dieter L, Duman RS (2013) Altered expression of synapse and glutamate related genes in post-mortem hippocampus of depressed subjects. Int J Neuropsychopharmacol 16:69-82. CrossRef Medline

Dworkin RH, Gitlin MJ (1991) Clinical aspects of depression in chronic pain patients. Clin J Pain 7:79-94. CrossRef Medline

Esteban JA, Shi SH, Wilson C, Nuriya M, Huganir RL, Malinow R (2003) 
PKA phosphorylation of AMPA receptor subunits controls synaptic trafficking underlying plasticity. Nat Neurosci 6:136-143. CrossRef Medline

Fields HL (2007) Understanding how opioids contribute to reward and analgesia. Reg Anesth Pain Med 32:242-246. Medline

Gear RW, Aley KO, Levine JD (1999) Pain-induced analgesia mediated by mesolimbic reward circuits. J Neurosci 19:7175-7181. Medline

Geha PY, Baliki MN, Harden RN, Bauer WR, Parrish TB, Apkarian AV (2008) The brain in chronic CRPS pain: abnormal gray-white matter interactions in emotional and autonomic regions. Neuron 60:570-581. CrossRef Medline

Golden SA, Christoffel DJ, Heshmati M, Hodes GE, Magida J, Davis K, Cahill ME, Dias C, Ribeiro E, Ables JL, Kennedy PJ, Robison AJ, GonzalezMaeso J, Neve RL, Turecki G, Ghose S, Tamminga CA, Russo SJ (2013) Epigenetic regulation of RAC1 induces synaptic remodeling in stress disorders and depression. Nat Med 19:337-344. CrossRef Medline

Gonçalves L, Silva R, Pinto-Ribeiro F, Pêgo JM, Bessa JM, Pertovaara A, Sousa N, Almeida A (2008) Neuropathic pain is associated with depressive behaviour and induces neuroplasticity in the amygdala of the rat. Exp Neurol 213:48-56. CrossRef Medline

Hao JX, Shi TJ, Xu IS, Kaupilla T, Xu XJ, Hökfelt T, Bartfai T, WiesenfeldHallin Z (1999) Intrathecal galanin alleviates allodynia-like behaviour in rats after partial peripheral nerve injury. Eur J Neurosci 11:427-432. CrossRef Medline

Hashimoto K (2009) Emerging role of glutamate in the pathophysiology of major depressive disorder. Brain Res Rev 61:105-123. CrossRef Medline

Hu B, Doods H, Treede RD, Ceci A (2009) Depression-like behaviour in rats with mononeuropathy is reduced by the CB2-selective agonist GW405833. Pain 143:206-212. CrossRef Medline

Isaac JT, Ashby MC, McBain CJ (2007) The role of the GluR2 subunit in AMPA receptor function and synaptic plasticity. Neuron 54:859-871. CrossRef Medline

Ito I, Tanabe S, Kohda A, Sugiyama H (1990) Allosteric potentiation of quisqualate receptors by a nootropic drug aniracetam. J Physiol 424:533543. Medline

Ji G, Neugebauer V (2011) Pain-related deactivation of medial prefrontal cortical neurons involves mGluR1 and GABA(A) receptors. J Neurophysiol 106:2642-2652. CrossRef Medline

Ji G, Sun H, Fu Y, Li Z, Pais-Vieira M, Galhardo V, Neugebauer V (2010) Cognitive impairment in pain through amygdala-driven prefrontal cortical deactivation. J Neurosci 30:5451-5464. CrossRef Medline

Jin R, Clark S, Weeks AM, Dudman JT, Gouaux E, Partin KM (2005) Mechanism of positive allosteric modulators acting on AMPA receptors. J Neurosci 25:9027-9036. CrossRef Medline

Jordan BA, Fernholz BD, Boussac M, Xu C, Grigorean G, Ziff EB, Neubert TA (2004) Identification and verification of novel rodent postsynaptic density proteins. Mol Cell Proteomics 3:857-871. CrossRef Medline

Jørum E, Warncke T, Stubhaug A (2003) Cold allodynia and hyperalgesia in neuropathic pain: the effect of $N$-methyl-D-aspartate (NMDA) receptor antagonist ketamine-a double-blind, cross-over comparison with alfentanil and placebo. Pain 101:229-235. CrossRef Medline

Kalivas PW, Volkow ND (2005) The neural basis of addiction: a pathology of motivation and choice. Am J Psychiatry 162:1403-1413. CrossRef Medline

Kim H, Chen L, Lim G, Sung B, Wang S, McCabe MF, Rusanescu G, Yang L, Tian Y, Mao J (2012) Brain indoleamine 2,3-dioxygenase contributes to the comorbidity of pain and depression. J Clin Invest 122:2940-2954. CrossRef Medline

Li N, Lee B, Liu RJ, Banasr M, Dwyer JM, Iwata M, Li XY, Aghajanian G, Duman RS (2010a) mTOR-dependent synapse formation underlies the rapid antidepressant effects of NMDA antagonists. Science 329:959-964. CrossRef Medline

Li XY, Ko HG, Chen T, Descalzi G, Koga K, Wang H, Kim SS, Shang Y, Kwak C, Park SW, Shim J, Lee K, Collingridge GL, Kaang BK, Zhuo M (2010b) Alleviating neuropathic pain hypersensitivity by inhibiting PKMzeta in the anterior cingulate cortex. Science 330:1400-1404. CrossRef Medline

Lim BK, Huang KW, Grueter BA, Rothwell PE, Malenka RC (2012) Anhedonia requires MC4R-mediated synaptic adaptations in nucleus accumbens. Nature 487:183-189. CrossRef Medline

Liu SJ, Zukin RS (2007) Ca2+-permeable AMPA receptors in synaptic plasticity and neuronal death. Trends Neurosci 30:126-134. Medline

Lynch G, Gall CM (2006) Ampakines and the threefold path to cognitive enhancement. Trends Neurosci 29:554-562. Medline
Machado-Vieira R, Salvadore G, Diazgranados N, Zarate CA Jr (2009) Ketamine and the next generation of antidepressants with a rapid onset of action. Pharmacol Ther 123:143-150. CrossRef Medline

MacQueen G, Frodl T (2011) The hippocampus in major depression: evidence for the convergence of the bench and bedside in psychiatric research? Mol Psychiatry 16:252-264. CrossRef Medline

Magnusson JE, Martin RV (2002) Additional evidence for the involvement of the basal ganglia in formalin-induced nociception: the role of the nucleus accumbens. Brain Res 942:128-132. Medline

Mickey BJ, Sanford BJ, Love TM, Shen PH, Hodgkinson CA, Stohler CS, Goldman D, Zubieta JK (2012) Striatal dopamine release and genetic variation of the serotonin $2 \mathrm{C}$ receptor in humans. J Neurosci 32:93449350. CrossRef Medline

Miller LR, Cano A (2009) Comorbid chronic pain and depression: who is at risk? J Pain 10:619-627. CrossRef Medline

Muschamp JW, Van't Veer A, Parsegian A, Gallo MS, Chen M, Neve RL, Meloni EG, Carlezon WA Jr (2011) Activation of CREB in the nucleus accumbens shell produces anhedonia and resistance to extinction of fear in rats. J Neurosci 31:3095-3103. CrossRef Medline

Mutso AA, Radzicki D, Baliki MN, Huang L, Banisadr G, Centeno MV, Radulovic J, Martina M, Miller RJ, Apkarian AV (2012) Abnormalities in hippocampal functioning with persistent pain. J Neurosci 32:5747-5756. CrossRef Medline

Navratilova E, Xie JY, Okun A, Qu C, Eyde N, Ci S, Ossipov MH, King T, Fields HL, Porreca F (2012) Pain relief produces negative reinforcement through activation of mesolimbic reward-valuation circuitry. Proc Natl Acad Sci U S A 109:20709-20713. CrossRef Medline

Nestler EJ, Hyman SE (2010) Animal models of neuropsychiatric disorders. Nat Neurosci 13:1161-1169. CrossRef Medline

Nestler EJ, Carlezon WA Jr (2006) The mesolimbic dopamine reward circuit in depression. Biol Psychiatry 59:1151-1159. CrossRef Medline

Nishizaki T, Matsumura T (2002) The aniracetam metabolite 2-pyrrolidinone induces a long-term enhancement in AMPA receptor responses via a CaMKII pathway. Brain Res Mol Brain Res 98:130-134. CrossRef Medline

Onozawa K, Yagasaki Y, Izawa Y, Abe H, Kawakami Y (2011) Amygdalaprefrontal pathways and the dopamine system affect nociceptive responses in the prefrontal cortex. BMC Neurosci 12:115. CrossRef Medline

Park SK, Nguyen MD, Fischer A, Luke MP, Affar el B, Dieffenbach PB, Tseng HC, Shi Y, Tsai LH (2005) Par-4 links dopamine signaling and depression. Cell 122:275-287. CrossRef Medline

Pezawas L, Meyer-Lindenberg A, Drabant EM, Verchinski BA, Munoz KE, Kolachana BS, Egan MF, Mattay VS, Hariri AR, Weinberger DR (2005) 5-HTTLPR polymorphism impacts human cingulate-amygdala interactions: a genetic susceptibility mechanism for depression. Nat Neurosci 8:828-834. CrossRef Medline

Pliakas AM, Carlson RR, Neve RL, Konradi C, Nestler EJ, Carlezon WA Jr (2001) Altered responsiveness to cocaine and increased immobility in the forced swim test associated with elevated cAMP response elementbinding protein expression in nucleus accumbens. J Neurosci 21:73977403. Medline

Ressler KJ, Mayberg HS (2007) Targeting abnormal neural circuits in mood and anxiety disorders: from the laboratory to the clinic. Nat Neurosci 10:1116-1124. CrossRef Medline

Restituito S, Khatri L, Ninan I, Mathews PM, Liu X, Weinberg RJ, Ziff EB (2011) Synaptic autoregulation by metalloproteases and gamma-secretase. J Neurosci 31:12083-12093. CrossRef Medline

Sanacora G, Treccani G, Popoli M (2012) Towards a glutamate hypothesis of depression: an emerging frontier of neuropsychopharmacology for mood disorders. Neuropharmacology 62:63-77. CrossRef Medline

Scott DJ, Stohler CS, Egnatuk CM, Wang H, Koeppe RA, Zubieta JK (2008) Placebo and nocebo effects are defined by opposite opioid and dopaminergic responses. Arch Gen Psychiatry 65:220-231. CrossRef Medline

Serulle Y, Zhang S, Ninan I, Puzzo D, McCarthy M, Khatri L, Arancio O, Ziff EB (2007) A GluR1-cGKII interaction regulates AMPA receptor trafficking. Neuron 56:670-688. CrossRef Medline

Sesack SR, Grace AA (2010) Cortico-basal ganglia reward network: microcircuitry. Neuropsychopharmacology 35:27-47. CrossRef Medline

Skolnick P (2008) AMPA receptors: a target for novel antidepressants? Biol Psychiatry 63:347-348. CrossRef Medline 
Skolnick P, Popik P, Trullas R (2009) Glutamate-based antidepressants: 20 years on. Trends Pharmacol Sci 30:563-569. CrossRef Medline

Sun X, Zhao Y, Wolf ME (2005) Dopamine receptor stimulation modulates AMPA receptor synaptic insertion in prefrontal cortex neurons. J Neurosci 25:7342-7351. CrossRef Medline

Tan CH, He X, Yang J, Ong WY (2006) Changes in AMPA subunit expression in the mouse brain after chronic treatment with the antidepressant maprotiline: a link between noradrenergic and glutamatergic function? Exp Brain Res 170:448-456. CrossRef Medline

Tukey DS, Ferreira JM, Antoine SO, D’amour JA, Ninan I, Cabeza de Vaca S, Incontro S, Wincott C, Horwitz JK, Hartner DT, Guarini CB, Khatri L, Goffer Y, Xu D, Titcombe RF, Khatri M, Marzan DS, Mahajan SS, Wang J, Froemke RC, et al. (2013) Sucrose ingestion induces rapid AMPA receptor trafficking. J Neurosci 33:6123-6132. CrossRef Medline

Vialou V, Robison AJ, Laplant QC, Covington HE 3rd, Dietz DM, Ohnishi YN, Mouzon E, Rush AJ 3rd, Watts EL, Wallace DL, Iñiguez SD,
Ohnishi YH, Steiner MA, Warren BL, Krishnan V, Bolaños CA, Neve RL, Ghose S, Berton O, Tamminga CA, et al. (2010) DeltaFosB in brain reward circuits mediates resilience to stress and antidepressant responses. Nat Neurosci 13:745-752. CrossRef Medline

Wang J, Goffer Y, Xu D, Tukey DS, Shamir DB, Eberle SE, Zou AH, Blanck TJ, Ziff EB (2011) A single subanesthetic dose of ketamine relieves depression-like behaviors induced by neuropathic pain in rats. Anesthesiology 115:812-821. CrossRef Medline

Yuen EY, Wei J, Liu W, Zhong P, Li X, Yan Z (2012) Repeated stress causes cognitive impairment by suppressing glutamate receptor expression and function in prefrontal cortex. Neuron 73:962-977. CrossRef Medline

Zubieta JK, Smith YR, Bueller JA, Xu Y, Kilbourn MR, Jewett DM, Meyer CR, Koeppe RA, Stohler CS (2001) Regional mu opioid receptor regulation of sensory and affective dimensions of pain. Science 293:311-315. CrossRef Medline 